\title{
Guanajuato, una bibliografía comentada, 1750-1917
}

\author{
Rosalía Aguilar, Claudia Burr, Claudia Canales, Rosa Ma. Sánchez de \\ Tagle
}

La bibliografía presentada a continuación es resultado de una rigurosa selección del material que arrojó la búsqueda en las principales bibliotecas públicas de la ciudad de México y el estado de Guanajuato. Si bien las fuentes obtenidas en el primer rastreo general fueron abundantes -casi 2000 títulos-, las obras aquí reseñadas suman aproximadamente un centenar, ya que se eligieron sólo aquellas que contenían una visión analítica o interpretativa sobre el proceso histórico guanajuatense. Asimismo, se eliminaron todos aquellos impresos relativos a decretos, memorias, proclamas, manifiestos, reglamentos y leyes pues aunque resultan muy importantes para el estudio de diversos fenómenos regionales, son más bien objeto de otro tipo de análisis. Por último, también se excluyeron las numerosas biografias de los próceres del estado, ante la necesidad de rescatar prioritariamente los textos que rebasaran las aproximaciones personalistas o hagiográficas y proporcionaran marcos referenciales más amplios. Así pues, sólo en el caso de etapas escasamente trabajadas, se seleccionaron estudios biográficos para cubrir, siquiera parcialmente, las múltiples lagunas existentes.

Es fundamental subrayar que las reseñas aluden a obras publicadas desde mediados del siglo XVIII hasta el año de 1917. La inclusión del periodo colonial obedece al hecho de que sin la referencia a éste. sería imposible comprender tanto el proceso de la insurgencia -que se gesta justamente en el contexto regional-, como el desarrollo del estado en la etapa republicana. No es gratuito que sea el final de la Colonia (1750-1821) la época más rica en material bibliográfico: Guanajuato fue en aquellos años no solamente la intendencia más próspera del virreinato, sino también una zona cuyas características marcarian algunos de sus derroteros ulteriores.

Pese a la relevancia de la región para la vida nacional, es sorprendente la manifiesta pobreza de estudios en torno a gran parte del siglo XIX. concretamente, desde la consumación de la Independencia hasta la restauración de la República. En cierto modo, el interés por la historia de Guanajuato se centra tan sólo en sus dos momentos de mayor proyección, es decir, el borbónico y el porfirista, ambos caracterizados por una extraordinaria producción minera y por la bonanza que de ella se desprende. Por lo tanto, el Guanajuato aparentemente en "crisis", la región supuestamente "deprimida", ha sido ignorada de manera sistemática tanto por la historiografía nacional, como por la local.

Dentro de este panorama bibliográfico revisten especial interés algunos trabajos monográficos sobre ciudades y municipios, en los cuales se encuentran dispersas una serie de pistas y sugerencias 
para la historia del estado. En este punto conviene subrayar la urgencia de más estudios de este tipo, ante la nula información sobre muchas poblaciones del estado cuyos procesos particulares no se puede seguir ignorando.

$\mathrm{Al}$ intentar un balance general de la historiografía guanajuatense debemos señalar varias características que si bien resultan poco halagüeñas, pueden verse también como un reto para el investigador. Salvo contadas excepciones, es notable la falta de textos que intenten abarcar en forma rigurosa y sistemática largos trechos de la historia regional. En vista de ello, y debido a la abundancia de aproximaciones fragmentarias, es difícil rastrear la continuidad de muchos fenómenos específicos. Fuera de la minería, que constituye el aspecto más estudiado gracias al esfuerzo de muchos técnicos y al interés que despertaba en los viajeros, pocos son los temas que pueden seguirse a través de varias etapas y localidades. Sobre la agricultura, el comercio, la educación, los movimientos migratorios y una infinidad de asuntos que conforman el proceso socioeconómico de Guanajuato. no se tienen, por desgracia, sino visiones muy parceladas.

Esta situación apunta hacia otro de los rasgos distintivos de la historiografia local, a saber, su clara preferencia por las cuestiones político-administrativas y enfocadas desde la perspectiva de la historia nacional. De este modo, son contadas las obras que han logrado sacudirse el peso del centralismo historiográfico, lo cual explica en parte la ausencia de una periodización que refleje la realidad propia del proceso regional.

Sin embargo, un aspecto promisorio dentro de este panorama son las aportaciones sobresalientes de las nuevas tendencias historiográficas, que si bien en su mayoría son obra de extranjeros, han abierto una brecha fundamental para la conceptualización de diversos fenómenos. Tal es el caso, por ejemplo, de los enfoques socioeconómicos sobre la naturaleza y función misma del espacio regional: la relación entre ciclos agrícolas, epidemias y movimientos demográficos: la conformación étnica y su relación con las mentalidades: y el modus operandi del poder político a nivel local. No obstante, estos estudios se centran, una vez más, en la última etapa del periodo colonial, quedando aún pendiente la aplicación de dichos enfoques al siempre postergado siglo XIX.

Las carencias bibliográficas se explican por una diversidad de factores, de los cuales no es el menos importante el desorden en que se encuentran muchos archivos y bibliotecas guanajuatenses. Esta situación, aunada a la escasez de estímulos e instrumentos para la producción intelectual, nos obliga a revalorar la labor, sin duda encomiable, de muchos historiadores locales.

Por último, quisiéramos que la lectura de estos comentarios invite a la investigación y a la reflexión sobre el fascinante pasado de la región guanajuatense. 


\begin{abstract}
BCUG Aguilar, Rosalia. Claudia Burr y Claudia Canales, s/c Perfil de una villa criolla. San Miguel el Grande, AHAG 1555-1810. México, Instituto Nacional de AntropoloAHUG gía e Historia, 1986, 135 p., maps., cuads. (Colecs/c ción Museos).

CRG INAH Trabajo originalmente concebido para servir de $\mathrm{s} / \mathrm{c}$ base a un museo local, sintetiza el proceso de formación y consolidación de San Miguel el Grande durante la época colonial, considerando a la villa en el contexto socioeconómico del Bajio y haciendo hincapié en los efectos que tuvieron sobre ella las reformas borbónicas. Las autoras aluden a aspectos tales como el criollismo característico de los habitantes, la tradición industrial y comercial, la importancia de los cuerpos de milicias y la formación y personalidad de Ignacio Allende. Basada en fuentes secundarias y enriquecida con interesantes apéndices, la obra también señala las lagunas existentes en la historia de la localidad y sugiere numerosos temas para futuros trabajos.
\end{abstract}

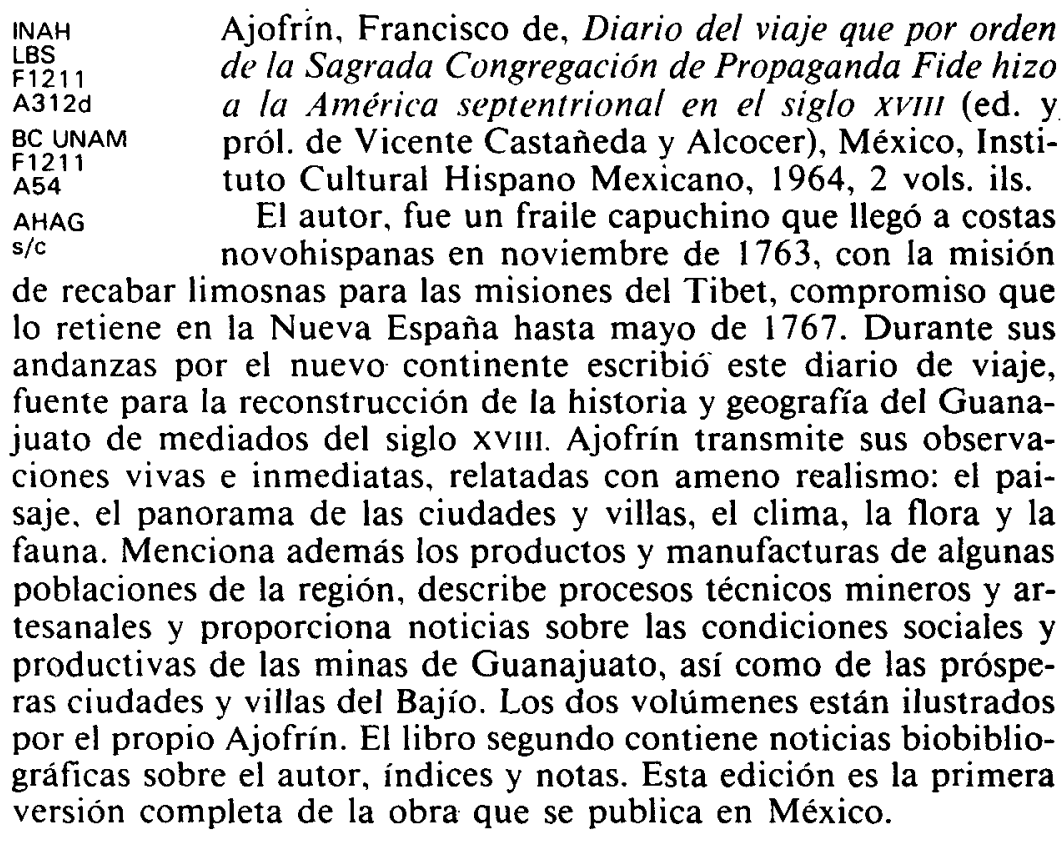

BOB INAH Alamán, Lucas, Historia de México: desde los prime${ }_{972.08}^{\mathrm{Rr}}$ ros movimientos que prepararon su independencia en A53h $\quad$ el año de 1808 hasta la época presente, México, ImBC UNAM prenta de J. M. Lara, 1849, 5 vols.

$\begin{array}{lll}\text { F1232 } & \text { Esta obra clásica, representativa del punto de vista } \\ \text { A418 } & \end{array}$ BMDR conservador sobre la Independencia y las primeras s/c experiencias republicanas, abarca desde las postrimerías de la Colonia hasta el año de 1852. Aunque es una historia general de México, la información sobre Guanajuato es amplia tanto por ser la tierra natal del autor como por constituir uno de los principales escenarios de las luchas insurgentes y, más aún, por poseer muchas de las fuentes de riqueza económica que tanto preocupaban al autor. Además de los innumerables hechos políticos y militares ocurridos en territorio guanajuatense, analiza importan- 
tes aspectos económicos y sociales, si bien con una visión apasionada mas no por ello menos aguda y minuciosa. Sus detalladas relaciones de los movimientos guerrilleros regionales, sus muy particulares retratos de los jefes insurgentes y sus observaciones sobre la agricultura, la minería y el comercio del Bajio, hacen imprescindible la consulta de esta obra para el estudio de la historia guanajuatense.

BOB INAH

972.03

A53e

BIM

972.03

ALA.e

Alamán, Lucas, et al., Episodios históricos de la guerra de Independencia. México, Imprenta de "El Tiempo" de Victoriano Agüeros, 1910, 2 vols.

Publicada con motivo del centenario de la Independencia, la obra reúne más de cincuenta episodios de la guerra, narrados por los autores más diversos. Hecha con el fin de difundir ampliamente las hazañas insurgentes, la antología tiene un valor más literario que histórico, pues recoge relatos novelados y sin ningún rigor científico. Su mérito estriba en proporcionar la visión lírica de plumas tan notables como las de Payno, Prieto, Altamirano, Otero, González Obregón, Pérez Verdia y muchos otros.

BCUG

422.09724

CON

BOB INAH

972.41

M $45 \mathrm{~m}$

Antúnez Echegaray, Francisco, Monografía histórico minera del Distrito de Guanajuato, México, Consejo de Recursos Naturales no Renovables, 1964, 588 p., plans., cuads., gráfs.

Este trabajo es el más completo hasta ahora sobre la minería guanajuatense, ya que abarca desde el descubrimiento de los primeros yacimientos en el siglo XVI. hasta el año de 1960 . Abarca los aspectos geológicos, técnicos y productivos de las minas, haciendo referencia a sus principales propietarios coloniales y a sus efectos sobre la vida y fisonomía de la ciudad. Su mayor mérito radica en el esfuerzo de trazar las líneas generales de la actividad minera a lo largo de cuatrocientos años, intentando visiones de conjunto que tanta falta hacen en el panorama historiográfico regional. Aunque con ciertos desequilibrios en el tratamiento de las distintas épocas y sin referencias a los problemas laborales y sociales de los mineros, este libro, más descriptivo que interpretativo, es un texto básico para el estudio del tema.

INAH

LDS

F1281

A7

COLMEX

342.72

A65779

COLMICH

20071

BCUNAM

F1281

A72
Arenas Guzmán, Diego, Guanajuato en el Congreso Constitulente, México, Patronato del Instituto Nacional de Estudios Históricos de la Revolución Mexicana-Secretaría de Gobernación, 1972, 201 p.

Recopilación de las intervenciones oratorias de los diputados guanajuatenses en el Congreso Constituyente, reunido en Querétaro a fines de 1916. Participante él mismo de las luchas políticas e ideológicas de la Revolución, el autor, partidario de Madero, reproduce los principales discursos de los representantes de Guanajuato desde los debates sostenidos en la presentación de credenciales hasta las palabras pronunciadas en la sesión de clausura del 31 de enero de 1917. La obra reúne los puntos de vista de hombres 
como Hilario Medina, José Natividad Macías, Enrique Colunga, Fernando Lizardi, Jesús López Lira, Manuel Aranda, Ramón Frausto, Vicente Valtierra, David Peñaflor, Carlos Ramírez Llaca, Luis Fernández Martinez, Francisco Diaz Barriga, Ignacio López y José Villaseñor sobre temas tales como la política obrera, la educación. la cuestión agraria, la posición frente al clero, etc. Particular interés reviste el capítulo en torno a las álgidas discusiones suscitadas en el Constituyente ante la iniciativa de anexar al estado de Querétaro varios distritos guanajuatenses.

AHAG
s/c
BAO UG
s/c

Arenas Sánchez, José, "El Padre D. Celedonio Domeco Jarauta y Ortiz en la invasión norteamericana", en Revista de la Universidad de Guanajuato, núm. 30, junio de 1970, p. 11-21.

Ante la importancia de una figura como la del padre Jarauta y la escasez de estudios profundos sobre su participación regional, es imprescindible mencionar este breve articulo que resume la campaña guerrillera emprendida por el sacerdote español en contra de los invasores norteamericanos. El autor se detiene particularmente en la toma de la ciudad de Guanajuato, donde Jarauta fue aprehendido por las fuerzas de Anastasio Bustamante.

BCUG
G
972.02
ARE
AHUG
S/c

Arenas Sánchez, José, Historia de la Alhóndiga de Granaditas, Guanajuato, Universidad de Guanajuato, 1969, 390 p. ils.

Con base en fuentes de primera mano, se reconstruye el proceso de construcción de la Alhóndiga de Granaditas. Insertando numerosos documentos, el autor contribuye a recrear la imagen de la sociedad de la época y sugiere temas interesantes sobre su agricultura y su economia. Se trata, en sintesis, del trabajo más completo sobre la historia de un edificio estrechamente ligado a la vida de la ciudad de Guanajuato.

COLMEX 549.98 $1325 \mathrm{~lm}$

\section{5,442 p.}

Bargalló, Modesto, La mineria y la metalurgia en la América española durante la época colonial, México-Buenos Aires, Fondo de Cultura Económica,

Escrito con motivo del cuarto centenario de la invención del método de amalgamación o "de patio", este libro intenta, entre otras cosas, destacar la importancia de dicha aportación debida al talento del metalúrgico español Bartolomé de Medina. Aborda básicamente los casos de Nueva España y el Perú, concentrándose sobre todo en los aspectos técnicos y muy especialmente en los procesos de beneficio. Sin desdeñar otros asuntos relativos al auge minero colonial, el autor analiza la legislación, la comercialización y la acuñación, así como varias discusiones de la época en torno a los métodos americanos y su legado a la metalurgia universal. La obra constituye sin duda un magnífico marco de referencia para el estudio de la minería en Guanajuato, ya que contiene múltiples referencias a ese real de minas. 


\begin{tabular}{|c|c|c|}
\hline $\begin{array}{l}\text { BC UNAM } \\
8 \mathrm{Y} 775 \\
\text { B } 38\end{array}$ & $\begin{array}{l}\text { BOB INAH } \\
972.06 \\
\text { B } 39 b\end{array}$ & $\begin{array}{l}\text { Bazant, Jan, Los bienes de la Iglesia en } \\
\text { México, 1856-1875. Aspectos económi- }\end{array}$ \\
\hline $\begin{array}{l}\text { NAH } \\
\text { BS } \\
\text { vi }>75 \\
43\end{array}$ & $\begin{array}{l}\text { AHUG } \\
\text { S/C } \\
\text { BMDR } \\
\text { S/C }\end{array}$ & $\begin{array}{l}\text { cos y sociales de la revolución liberal, } \\
\text { México, El Colegio de México, Centro } \\
\text { de Estudios Históricos, } 1971,346 \text { p. } \\
\text { (Nueva Serie, 13). }\end{array}$ \\
\hline
\end{tabular}

Aunque este trabajo trata más bien otras zonas de México, cabe llamar la atención sobre uno de sus apéndices, relativo al fraccionamiento de las haciendas del Bajio, donde se muestra a Guanajuato como uno de los estados más ricos en materia de bienes eclesiásticos. Desde una perspectiva socioeconómica, Bazant senala la importancia de las haciendas guanajuatenses e investiga el destino de algunas de ellas en fuentes de primera mano. Es precisamente por esto último que se considera imprescindible para el estudio del proceso de desamortización de las propiedades del clero.

$\begin{array}{ll}\text { BCUG } & \text { BOB INAH } \\ \text { S/C } & 972 \\ & \text { H58M } \\ \text { AML } & \text { CRG INAH } \\ \text { HE5 } & \text { S/C } \\ 2566 & \end{array}$

p. $460-480$, tabls., cuads.

Brading, David, "Grupos étnicos, clases y estructura ocupacional en Guanajuato, 1792", en Historia Mexicana, México, El Colegio de México, núm. 3 (83), vol. XXI, enero-marzo de 1972 ,

Breve pero consistente artículo, ofrece numerosas pistas e interpretaciones para la comprensión de la estructura social de la ciudad y el distrito de Guanajuato a finales del siglo xviII. Plantea nuevas e interesantes hipótesis en torno a la movilidad geográfica de los trabajadores mineros y proporciona datos estadísticos de fundamental importancia para futuras investigaciones. Todas sus fuentes son de primera mano.

$\begin{array}{ll}\text { BC UNAM } & \text { BCUG } \\ \text { TN28 } & 622.0972 \\ \text { B72 } & \text { BRA } \\ \text { INAH } & \text { AHAG } \\ \text { LBS } & \text { S/c } \\ \text { F1219.3 } & \\ \text { C6 } & \\ \text { B7 } & \\ \text { COLBAJ } & \\ 338.2 & \\ \text { BF99m } & \end{array}$

Brading, David, Mineros y comerciantes en el México borbónico (1763-1810), (trad. de Roberto Gómez Ciriza), México, Fondo de Cultura Económica, 1975 , 498 p., ils., maps., cuads.

Entre las obras más importantes de la historiografia colonial que se han publicado en los últimos veinte años, sobresale este novedoso estudio sobre un periodo crucial de nuestra historia. El autor dedica la tercera y última parte de su libro a Guanajuato, a fin de concretar las tesis desarrolladas en los capítulos anteriores. A mediados del siglo Xvili. el Bajío se había convertido en una zona bien diferenciada del resto de la Nueva Espana, en donde los efectos de las reformas borbónicas y la serie de cambios institucionales que llevaron aparejadas, desarticularon el equilibrio social, económico, político y regional. Esta situación se agravó con el gran desarrollo económico de las últimas décadas de la Colonia, cuando Guanajuato se convirtió en el mayor centro productor de plata del mundo y su minería alcanzó autonomia financiera. En los dos ültimos capítulos se describen algunas familias de la elite guanajuatense, formadas por grandes mineros y comerciantes, peninsulares $y$ 
criollos. que detentaban el poder económico y político a través de las diputaciones minera y mercantil y del ayuntamiento. La obra en su conjunto nos ofrece una sólida metodología, basada en una extensa investigación de fuentes primarias en archivos españoles y mexicanos, apoyada por una abundante bibliografia.

BOB INAH 330.980 F56h

CRG INAH $s / c$
Brading, David, "Estructura de la producción agrícola en el Bajío, 1700-1850", en Enrique Florescano (coord.), Haciendas, latifundios y plantaciones en América Latina. Siglo XXI Editores, 1978, p. 10531 . cuads.

En la linea de la historia económica, este ensayo aborda ciertos aspectos de las haciendas y ranchos del Bajío, señalando algunas particularidades que diferencian a esta zona agrícola de otras del centro de México y llamando la atención sobre fenómenos y procesos que están aún poco estudiados. Ilustrado con cuadros de distribución. producción y costos, el trabajo examina el caso de algunas propiedades del distrito de Pénjamo y el de otras pertenecientes al mariscal de Castilla, uno de los hacendados más notables de fines del siglo xvill. Pese a su brevedad, estas páginas proporcionan, con fuentes de primera mano, interesantes interpretaciones sobre los cambios que sufre la región en los últimoaǹos de la Colonia y el papel que desempeñan en el conjunto de la estructura los rancheros o pequeños propietarios.

COLMEX

333.32

$13799 \mathrm{~h}$

CRG INAH s/c

Brading, David, Haciendas and ranchos in the Mexican Bajio. León, 1700-1860, Cambridge, Cambridge University Press, 1978, 258 p.

Complemento de Mineros y comerciantes en el Mévico borbónico, se trata aqui de demostrar que las haciendas representaban una fuga continua para los excedentes de capital generados por la exportación. El autor examina el caso del Bajío -región donde tuvo mayor impacto la bonanza minera dieciochesca- y se concentra especificamente en la jurisdicción leonesa, por ser ésta la más ampliamente documentada. El resultado es un análisis de la estructura agraria y demográfica de León dentro de las lineas características de la historia económica: crecimiento y distribución poblacional, movilidad social, extensión y funcionamiento de las propiedades agrícolas, repercusiones de las crisis, etc. Son particularmente interesantes las aportaciones del autor respecto a la naturaleza de los hacendados, muchos de ellos mineros y comerciantes de otras zonas del Bajío, así como la caracterización y evolución de los rancheros, una de las categorías sociales más importantes y menos estudiadas de la región. La obra incluye, a manera de epílogo, un análisis de los efectos de la reforma agraria en el conjunto de la estructura.

BOB INAH 980 J68L

Este análisis de demografia histórica se basa en la interpretación de varios censos y registros parroquiales de bautismos, matri-
Brading, David y Celia Wu, "Population growth and crisis: Leon, 1720-1860", en Journal of Latin American Studies, año 5, nüm. 1, mayo de 1973, p. 1-36. 
monios y entierros, e intenta ahondar en el carácter del mestizaje que se dio en el Bajio, a la vez que constatar las tesis de Cooper, Florescano, Cook y Borah sobre las hambrunas y epidemias que asolaron al México borbónico. Centrado en el caso de la parroquia de León hasta el momento de su división en 1862, el trabajo de Brading y $\mathrm{Wu}$ señala las dificultades que enfrenta el investigador al manejar las fuentes disponibles y sugiere ciertas tendencias generales de la población que difieren de los enfoques tradicionales. Sin embargo, uno de sus aspectos más interesantes es la definición de crisis agrícola y las relaciones de ésta con las epidemias, asi como la descripción de ciertos efectos de la hambruna de 1785 en la parroquia leonesa.

\begin{tabular}{|c|c|c|}
\hline $\begin{array}{l}\text { BOB INAH } \\
\text { Rr } \\
972.03 \\
\text { B85g }\end{array}$ & $\begin{array}{l}\text { COLMICH } \\
31989\end{array}$ & $\begin{array}{l}\text { Bulnes, Francisco, La guerra de Inde- } \\
\text { pendencia. Hidalgo-Iturbide, pról. de Es- } \\
\text { tela Guadalupe Jiménez Codinach, in- }\end{array}$ \\
\hline $\begin{array}{l}\text { BC UNAM } \\
\text { F1232 } \\
\text { B9 }\end{array}$ & $\begin{array}{l}\text { AHAG } \\
\mathrm{s} / \mathrm{c}\end{array}$ & $\begin{array}{l}\text { dice de Golda Retchkeman, ed. facsim } \\
\text { lar, México, Ediciones El Caballit } \\
\text { S. A., 1982, XIV }-431-\text { XXIII p. }\end{array}$ \\
\hline
\end{tabular}

Obra poco conocida por las generaciones contemporáneas debido a su escasa difusión y por encontrarse agotada desde hace muchos años. Su reedición saca de nuevo a la luz un excelente trabajo iconoclasta. el cual intenta presentar a las figuras "polares en el debate clásico y amargo que ocupó más de medio siglo a liberales y conservadores..." La primera parte, relativa a Hidalgo, proporciona elementos muy interesantes para recuperar una visión regional de la formación del ejército insurgente, dentro del contexto ideológico e histórico del autor. Su punto de partida y su base documental son Lucas Alamán, Lorenzo de Zavala, Carlos Maria de Bustamante y José María Luis Mora.

BC UNAM

F1232

89513

AHAG

s/c

INAH

G. 0 .

Fi232.5

$\mathrm{B} 8$
Bustamante, Carlos María de, Culadro histórico de la revolución mexicana, iniciada el 15 de septiembre de 1810 por el C. Miguel Hidalgo y Costilla, cura del pueblo de Dolores en el Obispado de Michoacán, México, Comisión nacional para la celebración del sesquicentenario de la proclamación de la Independencia nacional y del cincuentenario de la Revolución

Desde su publicación en 1821, esta obra se convirtió en fuente obligada de cuantos escribieron y escriben sobre la revolución de Independencia. Si bien ha sido objeto de las más enconadas controversias a propósito de su método, su pasión y sus muy peculiares concepciones históricas, sus defectos nunca empañan ni el patriotismo que la inspiró, ni la magna labor de rescate de testimonios de muy diversa índole. Contiene buenos y largos párrafos sobre Guanajuato, ciudad principalísima en el movimiento de Independencia y forja la imagen heroica de Hidalgo, Allende, Aldama. Abasolo, etc., satanizando constantemente a los realistas. También se ocupa del Bajío en tanto que escenario de la guerrilla, al tiempo que es el forjador original de la leyenda local del 
Pípila, representante del minero insurgente. Esta obra clásica es sin duda alguna la piedra angular para el conocimiento de nuestra región y nuestra historia.

BOB INAH 330.972 C $37 \mathrm{~m}$ c. 2

Cardoso, Ciro (coord.), México en el siglo XIX (18211921). México. Editorial Nueva Imagen, 1981, $525 \mathrm{p}$.

Este trabajo colectivo aborda aspectos económicos y sociales de la transición de México al capitalismo y su etapa previa. Contiene varios capitulos que aluden al estado de Guanajuato y al Bajio, los cuales contribuyen a cubrir en parte las lagunas existentes en torno a ese periodo. Tales capitulos son: "Las estructuras agrarias" (Marco Bellingeri e Isabel Gil Sánchez), "La minería" (Ma. Cristina Urrutia de Stebelski y Guadalupe Nava Oteo) y "La minería bajo el porfiriato" (Guadalupe Nava Oteo). El libro en su conjunto constituye una valiosa aportación a la historia económica y proporciona un buen marco de referencia para abordar fenómenos regionales especificos.

AHAG 280c

Chávez, Tomás, Las minas de Guanajuato, los operarios mineros y' sus enfermedades. Memoria presentada por el doctor Tomás Chávez en el tercer Congreso Médico Mexicano, que se inauguró en Guadalajara el mes de julio de 1897, Guanajuato, Imprenta del Estado a cargo de Justo Palencia, 1897, $12 \mathrm{p}$.

Ponencia de un doctor en medicina, cuyo mérito es el de aludir a un aspecto fundamental de las poblaciones mineras que ha sido casi totalmente ignorado por la historiografía regional: las enfermedades propias de quienes trabajan en las minas de oro y plata. Analizando específicamente la leucemia, afección cuya incidencia coincide con las épocas de bonanza, muestra el descuido de la higiene en las labores de explotación y la falta de atención a ese renglón desde la época colonial hasta el Porfiriato.

BOB INAH $\mathrm{Rr}$

631.57272

C43d

BC UNAM

G8

$\mathrm{C} 43$

Chávez Orozco, Luis (comp.), Documentos sobre las alhöndigas de Celaya, Guanajuato y Oaxaca, México, Almacenes Nacionales de Depósito, S. A., 1955 , IX-20 p.

La encomiable tarea a que se abocó Luis Chávez Orozco, sabedor de la importancia que tienen para la historia los datos de carácter económico, se ilustra en esta recopilación de documentos que aporta luces para la historia colonial. Los testimonios relativos a las alhóndigas de Guanajuato y Celaya esclarecen las preocupaciones y quehaceres públicos que repercutían en la vida cotidiana de dichas ciudades. Chávez Orozco sugiere. mediante el planteamiento de hipótesis que en su momento fueron muy novedosas, una diversidad de temas para la investigación regional.

BOB INAH. Chávez Orozco, Luis (comp.), Documentos sobre las Rr 63157241 C43d alhöndigas de las villas de León y Salamanca de la Intendencia de Guanajuato. México, Almacenes Nacionales de Depósito, S. A., 1956, 28 p.

La publicación de estos documentos, que datan de la segunda 
mitad del siglo XVIII. constituye una notable aportación para abordar temas relacionados con las instituciones económicas y las cuestiones agricolas. La obra reúne materiales de archivo sobre la fundación de la alhóndiga de la villa de San Sebastián de León, así como información estadistica (nómina de labradores) y otros datos en torno a la compra, venta, contribuciones (alhondigaje y diezmos), préstamos, consumo de las haciendas, etc. El arreglo de las ordenanzas propuesto por los ayuntamientos al virrey y elaborado de acuerdo con las Leyes de Indias y sus correspondientes de Guanajuato y Celaya, proporcionan indicadores de las particularidades de la región.

Esta breve antologia de fuentes primarias, aporta algunas luces para el conocimiento de la historia económica de la región durante la dominación española. Entre otras cosas, puede verse cómo las peculiares funciones reguladoras del abasto de granos que cumplian las alhóndigas, afectaban muy directamente la vida cotidiana de las ciudades. El compilador es uno de los pioneros de la moderna historia económica y plantea hipótesis, en aquel momento muy novedosas, que invitan a abordar interesantes líneas de investigación.

CRG. INAH Díaz Polanco, Héctor, "Las clases sociales en el Bas/c jio". en Controversia, año 2, t. 1, núm. 5, Guadalajara. enero-marzo de 1978, p. 70-89.

Desde una perspectiva marxista, este ensayo analiza la oligarquia rural del municipio de Valle de Santiago. Cronológicamente, abarca la Independencia -si bien en forma sucinta-, la Reforma, el Porfiriato, la Revolución y la época contemporánea hasta el gobierno de Miguel Alemán (1946-1952), momento en el que se sientan las bases de la modernización agrícola. El autor concibe la estructura social como una "unidad dialéctica de la continuidad y discontinuidad" del proceso socioeconómico de la zona, a la vez que atribuye a la reforma agraria el papel de generar los cambios estructurales de la sociedad vallense.

BOB INAH 32333724 p $53 \mathrm{f}$

COLMEX

338.109724

D5426f

1982

Diaz Polanco, Héctor, Formación regional y burguesía agraria en Mérico. (Valle de Santiago, El Bajio). México, Editorial ERA, 1982, 215 p.

En cierto modo continuación del anterior, este libro sigue la trayectoria de la burguesia agraria de Valle de Santiago, delimitando sus características económicas y políticas dentro de la formación regional, e insertándola dentro del desarrollo global del capitalismo en México. Aunque se trata de una investigación de carácter sociológico, aporta un análisis histórico de este grupo social durante el periodo 19101960. Aprovechando el instrumental de la metodología marxista, postula además ideas interesantes sobre el doble carácter, rural y urbano, de este sector de la burguesia. 
COLMEX 338.109724 D5426a
Díaz Polanco, Héctor y Montandon Guye Laurent, Agricultura y sociedad en el Bajio. Siglo XIX, México. Juan Pablos Editor, 1984, 138 p.

Este trabajo se inserta dentro de los nuevos enfoques de los asuntos regionales que, paulatinamente, van llenando las lagunas. sobre algunos fenómenos económicos y sociales ignorados por la historiografía tradicional. Centrándose en el papel que desempeña la burguesía agraria de Valle de Santiago desde las postrimerias de la Independencia hasta el Porfiriato, los autores examinan la formación especifica de una estructura capitalista en esa zona del Bajío, sin dejar de tomar en cuenta procesos generales más amplios. Bien documentado en fuentes de primera mano, este libro arroja luz sobre ciertas particularidades de la región durante un periodo relativamente poco estudiado.

\begin{abstract}
BCUG
G

923.272

VIL

AML

HE1

2366 y 2367

Doblado, Manuel, Testimonios de un patriota (presentación de Othón Villela Larralde), Guanajuato, Gobierno del Estado, 1978, 219 p.

Realizada con el fin de "estaturar definitivamente la grandeza de este ilustre mexicano", el libro reúne documentos de Manuel Doblado, incluyendo manifiestos y circulares, asi como cartas escritas por o para él. Lo precede una biografia del político y diplomático guanajuatense, y reproduce diversos documentos que van desde el momento de la adhesión de Guanajuato al Plan de Ayutla, en septiembre de 1855, hasta la muerte de Doblado acaecida en Washington en junio de 1865. Es una colección de textos que proporciona una guía, aunque no completa, para conocer la participación de este político liberal en las luchas de su tiempo.
\end{abstract}

BOB INAH Rr332.4972 E54i

Elhuyar, Fausto de, Indagaciones sobre la amonedación en Nueva España, sistema observado desde su establecimiento, su actual estado y productos y auxilios que por este ramo puede prometerse la mineria para su restauración. Madrid. Imprenta de la calle de la Greda, 1818, 142 p.

Escrito en plena guerra de Independencia por el famoso director del Tribunal de Mineria de México, este opúsculo plasma algunas de las preocupaciones del autor ante los estragos causados por la revolución en la actividad minera. Gran conocedor de ésta y representante de los intereses de la Corona, Elhuyar intenta "reponer las cosas a su antiguo floreciente estado", pues a su modo de ver, de la minería depende el bienestar general. Así, examina detenidamente el ramo de la amonedación -por considerar que ahí pueden hallarse los medios más eficaces para rehabilitar toda la industria-. propone una serie de medidas para mejorarlo y confiere al Real Tribunal la responsabilidad de sacar al Cuerpo de Mineria de "la postración y desorden" en que se encuentra. Aunque la obra no se refiere a Guanajuato, constituye una lectura interesante tanto por las observaciones de Elhuyar sobre los problemas que originaba la guerra, como por la sintesis histórica de la política de amonedación y la crítica que le hace. 
IIH UNAM

F1391

G98E8

BOB INAH

972.41

$535 \mathrm{e}$

AML.

HE2

2443

Espinosa, Crispin y Manuel Sánchez Almaguer, Efemérides guanajuatenses o sean nuevos datos para contribuir a la historia de la ciudad de Guanajuato, Guanajuato, Editor Manuel Sánchez Almaguer, Imprenta y Encuadernación, 1920, 3 vols.

Según señala su título, esta obra es en cierto modo una continuación de la empresa iniciada por el padre Lucio Marmolejo a mediados del siglo XIX. Crispín Espinosa se dio a la tarea de asentar los principales hechos de la historia de la ciudad de Guanajuato, a partir de la fecha en que los dejó interrumpidos el sacerdote leonés. Después, a la muerte del propio Espinosa, fue Manuel Sánchez Almaguer quien continuó la consignación de los datos hasta el año de 1920. El mismo propósito de Marmolejo animó a estos dos autores, si bien la obra que nos ocupa es mucho menos conocida que la pionera. Se trata de un trabajo de recopilación en el que existe equilibrio en la temática de la información recabada, asi como en la reproducción textual de algunas notas periodisticas; sin embargo, no hay jerarquización en los datos, ni mucho menos aproximación interpretativa a los mismos. Pese a todo proporciona pistas interesantes para el investigador y constituyen. al lado de la obra de Marmolejo, una de las poquisimas fuentes para la historia de la ciudad de Guanajuato.

BOB-INAH Florescano, Enrique y Alejandra Moreno Toscano, noma de Puebla. 1977. 64 p.. maps.

El análisis del sector externo como la variable que determina el desarrollo regional del país. constituye la proposición de este trabajo. Destaca la necesidad de encontrar explicaciones de carácter histórico al ordenamiento espacial y su desarrollo en regiones con redes urbanas importantes. para después analizar tres casos de integración regional: el Bajio. Guadalajara, y los caminos de México-Veracruz por Jalapa y Orizaba (siglo XviII). Esta obra da luces para interpretar el papel de intercomunicación representado por las regiones, así como la repercusión de los cambios políticos en las fuerzas productivas. La investigación se sustenta en una buena selección documental y bibliográfica.

Colmex Fossey, Mathieu de, Le Mexique, Paris, Hann Plon

Partidario de la intervención francesa en México, el autor dedica este libro a la emperatriz Eugenia, pidiéndole que interceda ante su esposo para que ponga fin a la inestabilidad política que vive la nación y que impide la explotación adecuada de sus riquezas. Producto de su viaje por tierras mexicanas, la obra narra las impresiones del autor, quien dedica a Guanajuato gran parte del último capítulo. Como muchos otros viajeros, éste se interesa sobre todo en la minería, aunque no ignora aspectos agrícolas y demográficos. En suma, se trata de un libro fundamentalmente descriptivo que proporciona una visión extranjera sobre la región. 
BOB INAH 923 F84S

\section{$178 \mathrm{p}$.}

Fuentes Díaz, Vicente, Santos Degollado, el santo de la Reforma. México, Talleres Imprenta Arana, 1959,

Panegírico biográfico de quien, a juicio del autor, "encarna la más apasionante figura de la Reforma". Aunque guanajuatense de origen, Santos Degollado se desenvolvió política y militarmente fuera de su región natal, durante los años comprendidos entre la revolución de Ayutla y la guerra de Reforma. Esta participación del guanajuatense, su influencia determinante sobre Juárez para la expedición de las Leyes de Reforma y su contribución al triunfo definitivo de los liberales pese a las muchas derrotas sufridas en los campos de batalla, son algunos de los aspectos que intenta rescatar la obra, misma que se ve enriquecida con unas notas escritas por el propio Degollado durante los últimos meses de su vida.

BOB INAH

972.02

U55e

1971

Galaviz de Capdevielle. Ma. Elena, "Descripción y pacificación de la Sierra Gorda", en Estudios de historia nov'ohispana. México, UNAM. Instituto de Investigaciones Históricas, 1971, p. 113-49.

Ante la escasa bibliografia sobre la Sierra Gorda, escenario de una de las rebeliones campesinas más interesantes de mediados del siglo XIX. este estudio tiene el mérito de describir las características geográficas y étnicas de la región y de rastrear los levantamientos indigenas acaecidos en ella desde el siglo XVI. Aunque se refiere más bien a los esfuerzos pacificadores de los misioneros y autoridades coloniales. en las naciones chichimecas, el trabajo abarca también el periodo republicano y alude en forma resumida a la rebelión encabezada por Eleuterio Quiroz en 1847.

AHAG Galaviz de Capdevielle, Ma. Elena, Eleuterio Quiroz $s / c$ Y la rebelión de 1847 en Xichí, San Luis Potosí, Academia de Historia Potosina, 1979, 25 p. (Biblioteca de Historia Potosina, Serie Cuadernos, 69).

Descripción de los hechos de armas acaecidos en Xichú y otros puntos de la Sierra Gorda entre 1847 y 1849, como resultado de los movimientos rebeldes contra el gobierno federal al terminar la guerra con los Estados Unidos. Destaca la actitud asumida en la entidad por el gobierno de José Joaquín de Herrera y la actividad desplegada por éste para sofocar la rebelión que cundió rápidamente en una vasta zona, bajo el liderazgo de hombres como Eleuterio Quiroz. El aparato crítico que sustenta el trabajo está constituido por fuentes de primera y segunda mano.

BC UNAM

F1232

H624

BCUG

$S / C$

AHAG

$\mathrm{s} / \mathrm{c}$
Garcia, Pedro, Con el cura Hidalgo en la guerra de independencia, México, Empresas editoriales, 1948, 249 p. (El liberalismo mexicano en pensamiento y en acción, 1).

Es éste uno de los testimonios más emotivos sobre el movimiento del cura de Dolores, ya que su autor, además de ser ferviente partidario de la insurgencia, militó en sus filas iniciales. Muy cercano a Hidalgo y a Allende, el sencillo tendero sanmiguelense narra las primeras campañas de la guerra con 
realismo y amenidad, introduciendo algunas reflexiones sobre asuntos políticos y sociales y revelando un gran conocimiento de su región natal. Pese a su pasión por la causa, García no omite los desaciertos de sus jefes ni la confusión que en muchos momentos hizo presa entre sus participantes.

BC UNAM

TN28

G36

Garcia, Trinidad, Los mineros mexicanos; colección de articulos sobre tradiciones y narraciones mineras, descubrimientos de las minas mas notables, fundación de las poblaciones mineras más importantes y particularmente sobre la crisis producida por la baja de la plata. México, Editorial Porrúa, $19703^{\text {a }}$ ed., 399 p.

El autor, "minero de corazón", escribe esta amena obra con el objetivo fundamental de hacer una defensa de la mineria, en los momentos en que la industria pasaba por la crisis del último cuarto del siglo XIX. Vuelve su mirada hacia los operarios mineros, señalando las características esenciales que los consolidan como grupo social y como productor. Narra la historia del descubrimiento de los principales centros mineros del país, haciendo hincapié en la formación de las nuevas poblaciones que surgieron en los reales de minas, refiriéndose brevemente a Guanajuato durante el siglo XVI. Finalmente inserta una serie de artículos que había publicado en los periódicos, los cuales constituyen la parte medular de su defensa. Así en ocasiones con pasión y en otras con espiritu crítico el autor plantea las expectativas mineras frente a la crisis mundial por la que atravesaba la producción y la cotización de la plata. La obra, publicada por primera vez en 1895 , es un testimonio valioso para conocer la situación de la minería y sus operarios en el siglo XIX.

García Moyeda, Manuel, Compendio histórico del Obispado de León, Guanajuato, Imprenta de M. G. y M., $1881,52 \mathrm{p}$.

Este compendio narra los primeros diecisiete años de historia del obispado de León, desde su erección en febrero de 1864 hasta el 7 de junio de 1887 . Organiza en cuatro apartados la información relativa al territorio, parroquias y obras de la nueva diócesis, a fin de resaltar su importancia con respecto al obispado de Michoacán al que antes pertenecia. Además, incluye los datos biográficos de José María de Jesús Diez de Sollano y Dávalos, primer obispo de León, y relata los funerales y exequias que con motivo de su muerte se realizaron en todo el obispado. El autor utiliza como fuentes principales los documentos conservados en el archivo de la secretaria de la diócesis.

AHAG

S/C

BCUG

S/c

BAO.UG

$\mathrm{s} / \mathrm{c}$

González, Luis, "Ciudades y villas del Bajio", en Colmena Universitaria, año 9, núm. 48-49, Guanajuato, mayo-agosto de 1980 , p. 45-55.

Con la amenidad característica de los escritos de Luis González, este artículo expone una serie de rasgos propios de la vida urbana del Bajio dieciochesco.

Para tal efecto, el autor estudia someramente doce ciudades y 
villas abajeñas, comprendidas en los actuales estados de Guanajuato, Querétaro, Michoacán y Jalisco. Entre sus similitudes están la geografia. el clima. los antecedentes históricos desde tiempos prehispánicos, la economia, la cultura y la posición que adoptan frente al movimiento independentista. El padre de la microhistoria señala así doce puntos que definen el interesante proceso histórico "de los centros urbanos de esta importante, umbilical, maternal, nuclear, creadora región de México".

INAH
LIB
F1281
D5
G643a
BOB INAH
Rr
972.41
G65a
AHAG
S/C

González, Pedro, Apuntes históricos de la ciudad de Dolores Hidalgo, Celaya, Imprenta Económica, 1892 , 323 p., ils.

Obra de gran interés para la historia local en la que el autor, en su calidad de jefe político de ese departamento y con base en documentos hasta entonces desconocidos, expone una disertación sobre los pormenores de los sucesos ocurridos en Dolores la noche del 15 de septiembre de 1810 . El estudio comprende la narración de los hechos de armas ocurridos desde esa fecha hasta la aprehensión de los principales caudillos en Acatita de Baján. El propósito del libro es justificar la participación de Miguel Hidalgo en la lucha independentista y consagrarlo como su máximo jefe. Asimismo, señala los errores cometidos por Allende y la conducta de Aldama y Abasolo. Complementan el trabajo noticias sobre los lugares y monumentos de interés en la ciudad. Heliogrâfías y facsímiles de las firmas de los principales personajes de la guerra de Independencia en la región, ilustran la obra.

$\begin{array}{ll}\text { AHAG } & \text { BOB INAH } \\ \text { s/C } & \text { rr } \\ \text { COLBAJ } & 917.241 \\ 917.244 & \text { G65g } \\ \text { G6439 } & \text { COLMICH } \\ \text { INAH } & 917.241 \\ 20-4.18 & \text { GON9 }\end{array}$

González, Pedro, Geografia local del Estado de Guanajuato, Guanajuato, Imprenta de la Escuela Correccional, $1906,460 \mathrm{p}$.

Esta es la más completa descripción geográfica del estado de Guanajuato. El autor ocupó diversos cargos en la administración del estado y fue miembro distinguido de la Sociedad Mexicana de Geografía y Estadística y de la Sociedad "Antonio Alzate". Producto de casi veinticinco anoos de investigación rigurosa, esta magna obra, animada por un espíritu cientifico y enciclopédico, constituye una lectura obligada para el estudioso de Guanajuato. La información se divide en tres rubros: geografía física. geografia politica y geografía humana, a través de los cuales se reconstruye una amplia y amena visión de cada uno de los rincones del territorio guanajuatense.

BOB INAH González Arellano, Josefina, "El caudillo insurgente ${ }_{\text {A531 }}^{572}$ Albino García”, en Anales del INAH, época 6, 19(48), 1966, p. 251-254.

El propósito de la autora es dar a conocer algunos datos inéditos de la vida de Albino Garcia, obtenidos de documentos del Archivo Municipal de León. Gto. Sitúa de manera ordenada y consistente los hechos que suceden en el Bajio en torno al famoso guerri- 
llero y logra recuperar una visión muy clara del papel que desempeñaban las gavillas insurgentes y los ejércitos realistas en la región, durante los años de 1811 y 1812 . Contiene, además, interesantes materiales complementarios.

\begin{abstract}
BCUG
González Leal, Mariano, Crónicas de León. Relacio-

972.41

GON

AHAG

s.c.

nes, datos y documentos para la historia de la Perla del Bajio, León Lúmen, 1971, 250 p., ils.

Con el propósito de contribuir a las festividades

del Cuarto Centenario de la fundación de León, el

autor conforma esta obra monográfica, a base de fragmentos sobre la historia de la patria chica desde la época colonial hasta nuestros dias. Con estos fragmentos el Sr. González Leal elabora una relación de hechos históricos referentes a las fiestas, costumbres y tradiciones de la ciudad, así como de sus monumentos, obras públicas emprendidas a través del tiempo y de los personajes sobresalientes de la sociedad civil y eclesiástica leonesa. El libro está enriquecido con abundante material gráfico, entre el que se encuentra una iconografia de leoneses distinguidos, fotografías y planos antiguos de la ciudad, reproducciones de documentos, facsímiles de firmas, litografías y láminas relacionadas con León.
\end{abstract} najuatense, Guanajuato, Gobierno del Estado, 1985, 105 p., ils.

Con el estilo característico de muchos historiadores locales y empapado de conocimientos adquiridos a través de numerosos trabajos, de una esmerada tarea de investigación en archivos estatales, nacionales y extranjeros y del acopio de datos de heráldica y genealogia, el autor logra conformar un amplio marco histórico de la ciudad de Guanajuato para dar entrada a los hechos que se relacionan con su tema central: las transformaciones del actual Palacio Legislativo desde sus origenes más remotos. La obra ofrece al lector no sólo un rico fragmento de la historia de la capital del estado, sino también un retrato de la rancia nobleza local, vinculada, entre otras cosas, a la posesión de fincas urbanas. Es particularmente interesante el material gráfico.

AHAG

$\mathrm{s} / \mathrm{c}$

COLMICH

923.572

GUZj
Guzmán, Martín Luis, Javier Mina. Héroe de España y de México, México, Compañia General de Ediciones, S. A., 1973, $4^{\text {a }}$ ed., 236 p. (Colección Ideas, Letras y Vida).

Haciendo gala de su destreza para desarrollar la narración novelada de la historia, el autor recrea la figura de Javier Martín Mina. Destacando el carácter de la lucha del pueblo español contra el absolutismo monárquico y las fuerzas napoleónicas, se ubica a Mina dentro del contexto de la gran lucha de la época contra el despotismo. El libro relata con gran amenidad los 
pormenores de la expedición de Mina a México y su contacto con los insurgentes del Bajío. Señala, finalmente, las causas que contribuyeron al fracaso de su empresa.

BCug Guzmán Cíntora, J. Jesús, Yuririaptindaro, México, $\mathrm{S} / \mathrm{C}$ COLBAJ 972.41 G9931y s.e.. s.f., $3^{\mathrm{a}}$ ed.. 192 p., ils.

Sobre Yuririapúndaro, una de las poblaciones más antiguas e interesantes del estado, se han escrito algunas monografías que, si bien han logrado rescatar noticias y tradiciones, no han conseguido conformar una obra profunda y seria sobre la historia de la localidad. En esta sencilla monografia. el autor da una visión panorámica de la historia de Yuriria desde los tiempos prehispánicos hasta 1920, y destaca las figuras de los grandes personajes y héroes de la región. La parte dedicada a la Revolución. donde se relatan las vicisitudes padecidas por la población a causa del movimiento armado, se acerca más a una relación anecdótica que a una obra historiográfica propiamente dicha.

COlBAJ Hamnett, Brian R., "Anastasio Bustamante y la gues/c rra de Independencia, 1810-1821", en Historia Mexicana. vol. XXVIII, núm. 4 (112), abril-junio de 1979, p. 515-545.

El movimiento insurgente se mantiene vivo en Guanajuato desde que se gesta en Dolores hasta la consumación de la Independencia en 1821 . Toca a Anastasio Bustamante, jefe del bando realista, apoyar y llevar a buen fin la labor pacificadora de Agustín de Iturbide en la región, tan destruida por la guerra y tan codiciada por su riqueza. Este articulo pone de manifiesto, a través del análisis de la labor de Bustamante, la estrategia de los realistas y su plan contrainsurgente. El apoyo de fuentes documentales y la excelente selección bibliográfica permiten al autor aportar buenos elementos de comprensión y de análisis.

BOB INAH

330.972

Howe. Walter, The mining guild of New Spain and its $\mathrm{H} 68 \mathrm{~m}$

Tribunal Gencral 1770-1821. Cambridge. Harvard University Press. 1949, 518 p.

Esta monografía resulta imprescindible para el estudio de la mineria colonial, ya que analiza el surgimiento y desarrollo de dos instituciones borbónicas que no poco tuvieron que ver con el auge dieciochesco novohispano: el Cuerpo y el Tribunal de Mineria. Basándose en documentos inéditos de varios archivos, el autor señala los rasgos específicos de ambos organismos, a la vez que aborda el asunto de las ordenanzas del gremio y de la Escuela de Mineria. Dentro de un contexto más amplio, la obra contribuye a la comprensión de los mecanismos administrativos de la época, así como de ciertos aspectos financieros, tecnológicos y laborales de la industria minera. Aunque se trata de un trabajo general que abarca toda la Nueva España, las referencias a Guanajuato son por demás numerosas y útiles. Conviene subrayar que entre sus apéndices aparece reproducido integramente el informe de Fausto de Elhuyar sobre los métodos mineros guanajuatenses, presentado 
en 1789. Dicho informe no sólo proporciona un cuadro bastante completo de los procedimientos de extracción y beneficio empleados en la Veta Madre, sino que también ilustra sobre la inquietud cientifica y modernizadora de los enviados de la Corona española.

8cug Humboldt, Alejandro de, Ensayo politico sobre el G972.02 . reino de la Nueva España (estudio preliminar y notas de Juan Antonio Ortega y Medina), México, Edis/c. torial Porrúa, S. A., 1978, 696 p., ils., cuads. y maps (Colección "Sepan cuantos...", 39).

Esta es. sin duda, una de las obras más importantes para el estudio de la Nueva España en las postrimerias de la Colonia. Su carácter enciclopédico. su magnifica síntesis de una infinidad de materiales que habian sido recogidos por muchos sabios novohispanos y su riqueza en materia de observaciones cientificas. hacen de la obra uno de los productos más acabados del saber de su tiempo. A ella se debe no sólo el fortalecimiento de la conciencia criolla sobre la riqueza del territorio americano, sino el despertar en Europa de un interés hacia México que se traduciría, en el curso del siglo XIX, en la visita de muchos exploradores y viajeros cuyo punto de referencia será siempre el magno trabajo de Humboldt. La obra dedica una buena parte a la intendencia de Guanajuato, dado el gran interés del científico alemán por la fabulosa riqueza de sus minas. En este aspecto, la información humboldtiana constituye una fuente obligada, pues no sólo describe minuciosamente y con rigor las condiciones técnicas, económicas, sociales y laborales de los procesos mineros, sino que constantemente establece comparaciones entre los métodos novohispanos y los europeos. No obstante, el autor también dirigió su curiosidad hacia otros renglones de la vida guanajuatense. En su recorrido por la intendencia visitó no sólo los famosos centros mineros sino poblaciones como Celaya y Salamanca, los manantiales de Comanjilla, la sierra de Santa Rosa y la vasta zona agricola próxima a la frontera con Michoacán. Asimismo ofrece también muchas observaciones sobre el clima, el suelo, los sistemas de cultivo, el comercio, los caminos y la población, enriquecido todo por la amplia cultura y el afán sistematizador de este excepcional viajero.

$\begin{array}{ll}\text { INAH } & \text { BCUNAM } \\ \text { LBS } & \text { F1391 } \\ \text { HC137 } & \text { D6H86 } \\ \text { G83 } & \\ \text { H8 } & \\ \text { IIH UNAM } & \text { CRG INAH } \\ \text { F1391 } & \text { S/C } \\ \text { D6H86 } & \end{array}$

Hurtado López, Flor de María, Dolores Hidalgo. Estudio económico. 1740-1790. México. INAH. 1974, 128 p., cuads. (Colección Científica. Historia, 11).

Innovador estudio monográfico que aporta interesantes datos sobre la conformación económica de la Congregación de Nuestra Señora de los Dolores (hoy Dolores Hidalgo) en el siglo XVIII. Las fuentes utilizadas por la autora son los diezmos, con base en los cuales se analizan los movimientos y precios de la producción agrícola, relacionándolos con fluctuaciones cíclicas. Se destaca el grado de evolución económica alcanzado, a la vez que se hace un análisis sobre la estructura de la tenencia de la tierra en la localidad. El interés 
de la obra radica fundamentalmente en los métodos cuantitativos aplicados, que se resumen en los 52 cuadros y apéndices que complementan la investigación.

COLBAJ
CAT
552
AML
HE2
2418
BFL
S/C

Ibarra Grande, Jesús, Jaral de Berrio y su marquesado. Monografía histórica, León, s. e., 1983, 183 p., ils.

Esta monografia sobre el gran latifundio que tuvo por centro la opulenta hacienda de Jaral, ubicada en los linderos con San Luis Potosí, está conformada por una narración pormenorizada en torno a sus ricos propietarios. Se hace un estudio genealógico de la familia del capitân José de Retes y sus descendientes, que por más de doscientos años hicieron de esta hacienda la sede del mayorazgo y marquesado del Jaral de Berrio. Es muy escasa la información sobre la hacienda como unidad de producción; en cambio, incluye noticias de sucesos ocurridos en la hacienda durante la guerra de la Independencia, de los cambios de propietario y del desmembramiento final del latifundio en la década de 1940. Las fuentes documentales a las que recurre el autor proceden de archivos parroquiales y utiliza. por otra parte, una sucinta bibliografía.

BFM UG

KRA

CRG INAH

s/c

BCUG

G 338.2

338.2
KRA

AHAG

$\mathrm{s} / \mathrm{c}$
338.2097241

Krantz, Lasse, Minería y marginalidad. Ensayo socioeconómico sobre el desarrollo minero en Guanajuato, Guanajuato, Escuela de Ingeniería de Minas y Metalurgia de Guanajuato, 1978, 77 p., cuads., ils.

Este ensayo presenta una visión muy clara y sugestiva del desarrollo económico y social de Guanajuato. La primera parte se dedica a la historia de la mineria en Guanajuato desde la gran bonanza del siglo XvIII hasta el retiro de capitales extranjeros durante el periodo posrevolucionario del siglo $\mathrm{xx}$. A través de los factores de capital, tecnología y fuerza de trabajo se analiza el particular proceso de cambio de la minería guanajuatense y los efectos que se producen en la estructura ocupacional. En la segunda parte se presenta un estudio del caso de La Luz, poblado que surge en el siglo XIX como un importante centro minero y que en el actual se convierte en una pequeña comunidad rural. El aspecto histórico general se basa en fuentes secundarias, mientras que el caso concreto de La Luz se apoya en una investigación de campo. Debe señalarse. por último, que la versión castellana desmerece del original en inglés.

AHAG s.C. Ladd, Doris M., La nobleza mexicana en la época de la Independencia, 1780-1826. Trad. Marita Martínez del Rio de Redo, México, Fondo de Cultura Económica, 1984, 353 p.. cuads. y maps.

Recientemente, la función de las elites coloniales y su participación en el devenir histórico de México, ha llamado la atención de especialistas que se ocupan de ellas desde el punto de vista socioeconómico y sociopolítico. Dentro de la amplia e importante 
historiografía de la Independencia mnexicana, destaca este serio trabajo de investigación, que analiza precisamente el papel que la nobleza desempeñó antes. durante y después de la guerra. El estudio aporta nuevas perspectivas de interpretación, maneja hechos, instituciones y personajes que explican la participación e influencia de guanajuatenses en la formación, desarrollo y consolidación de la nobleza mexicana y su definición como grupo autónomo frente a su propia sociedad. Existen en esta obra, numerosas alusiones a la región de Guanajuato durante el movimiento insurgente y sobre las consecuencias de la guerra para la elite y sus posesiones. Entre las conclusiones de este trabajo, es fundamental aquella que apunta la necesidad de una investigación profunda sobre "la historia de las provincias donde las exigencias coloniales, las reformas borbónicas, la guerra, las innovaciones parlamentarias y los retos al centralismo desempeñaron su propio enfrentamiento". Guanajuato es una de ellas. La autora señala, asimismo, la urgencia por abordar estos procesos "con periodos que traten de superar la barrera de 1810 [sólo así], podremos apreciar grandes ciclos de cambio...".

COLMEX

378.7244

L269h

BCUG

G378.7241

LAN

AHAG s/c Estado desde su fundación por los jesuitas en 1732.

Lanuza. Agustin, Historia del Colegio del Estado de Guanajuato, México, M. León Sánchez, 1924, 428 p.

Escrita en tono panegírico y con un enorme acopio de información, esta obra proporciona la visión más completa con que se cuenta sobre el Colegio del como Colegio de la Purísima Concepción, hasta el establecimiento de la Escuela de Medicina en 1921. Escrito a la manera de los libros tradicionales hechos por aficionados a la historia, contiene datos biográficos de las figuras más notables de la institución, relaciones detalladas de sus aportaciones y fragmentos de sus discursos, asi como un sinnúmero de noticias sobre la legislación del plantel. la naturaleza de las cátedras, el número y calificaciones de los alumnos, etc. Es lectura obligada para cualquier historia de la educacirin $n$ de la cultura en Guanajuato.

BOB INAH

972.41

L57e

Lira, Sóstenes J., Efemérides de la ciudad de León; colección de datos y' documentos para la historia de la misma población. León. Imprenta de J. M. Rivera, 1914. $2^{\mathrm{i}}$ ed.. $246 \mathrm{p}$.

Se trata de una recopilación de datos sobre los sucesos notables ocurridos en la ciudad de León. El libro se inicia con una introducción en la que el autor hace una descripción de la ciudad en cuanto a localización, extensión, habitantes, clima, caracteristicas particulares, monumentos, industria, instituciones educativas y curatos que integran el obispado. Las efemérides se inician a partir de la fundación de la villa en el siglo XVI y terminan en 1911 . En algunos pasajes se alude a personajes célebres y datos históricos de interés. siendo las notas cronológicas correspondientes al siglo $\mathrm{XIX}$ las que conforman el grueso de la obra. La información que 
aporta sobre la organización de León como capital diocesana y su erección en obispado en 1863, presenta particular interés, al igual que la referencia a las festividades que, con motivo de la entrada de Maximiliano I a la capital, se llevaron a cabo en 1864. El autor transcribe algunos documentos de interés y menciona otros en algunas de sus notas, sin embargo, no cita la localización de sus fuentes.

CONDUMEX Marmolejo, Lucio, Efemérides guanajuatenses o da972.41

BCUG

$\mathrm{G}$

97.4

MAR tos para formar la historia de la ciudad de Guanajuato, Guanajuato, Imprenta, librería y papelería de Francisco Díaz, 1907, 4 vols.

Este es el primer intento de recopilación sistemática de datos para la historia de la ciudad de Guanajuato, desde el año de 1526 hasta 1884 , fecha cercana a la muerte del autor. Aunque la obra adolece de muchos errores, carece de interpretaciones, no cita fuentes y discrimina los aspectos económicos y sociales, sigue siendo muy socorrida debido a la escasez bibliográfica sobre el tema. No obstante el gran mérito del autor, urgen trabajos que lo rectifiquen y superen.

BIM

917.241

Martin, Percy F., Mexico's Treasure House (Guana-

MAR.m juato). An illustrated and descriptive account of the mines and their operations in 1906. New York, The Cheltenham Press. 1906, 259 p.

Resultado del estudio de un escritor y periodista inglés especializado en zonas e inversiones mineras, este libro muestra el entusiasmo extranjero por las amplias posibilidades de Guanajuato hacia fines de la era porfiriana. Convencido de que las minas guanajuatenses pueden proveer al mundo de los metales que "construirán el imperio del mañana", Martin aboca su trabajo a los inversionistas extranjeros, fundamentalmente británicos y estadunidenses, instándolos a aprovechar la magnífica oportunidad que ofrece la conjunción de un subsuelo privilegiado, un gobierno estable y los mejores intereses financieros de los Estados Unidos y Gran Bretaña. La obra está dividida en 16 capítulos, profusamente ilustrados con fotografías, gráficas y mapas. Partiendo de una serie de observaciones sobre las características geográficas, demográficas, sociales y culturales del distrito minero de Guanajuato, el autor toca a continuación los aspectos técnicos y laborales, para, al fin, emprender el análisis de las grandes compañias foráneas. subrayando sus propiedades, ganancias, equipo y aportaciones técnicas. Martin es especialmente prolijo en lo tocante a la actividad de los consorcios anglosajones, debido a su interés en ek incremento del capital extranjero en Guanajuato. La obra concluye con las relaciones biográficas de los empresarios y técnicos que. a juicio del autor, contribuyeron al auge de la zona. Una serie de observaciones sobre los costos y perspectivas de la explotación y administración minera en Guanajuato constituyen las conclusiones de la obra. 

de Irapuato, México, Editorial Castalia, 1965, 188 p.. ils. (Biblioteca Historia Mexicana).

El propósito de esta obra es rectificar errores que tradicionalmente se han venido repitiendo sobre algunos hechos de Irapuato. Para tal efecto, el autor recurre a fuentes documentales y trata de reconstruir a partir de éstas algunos aspectos sobre la colonización de la congregación. Para el periodo que cubre nuestro trabajo, son de especial interés los capítulos XVI-XXIII, donde el autor recopila valiosos datos sobre los grandes benefactores de la región y las obras emprendidas por ellos. Transcribe documentos sobre la creación de las escuelas de instrucción civil y popular a mediados del siglo Xvill (el Colegio franciscano para niños, y el de la Enseñanza para niñas), instituciones pioneras en la vida académica novohispana. A pesar de tocar temas tan interesantes, la obra no profundiza en la interpretación de las fuentes.
\end{abstract}

INAH
G.0.
F1281
M3
IIE UNAM
F1391
S2
M38
BCUG
G
972.41
MAZ
BMDR
S/C

Maza, Francisco de la, San Miguel de Allende. Su historia. Sus monumentos (pról. Manuel Toussaint), México, Unam, 1939, 216 p., ils.

Con especial énfasis en el aspecto arquitectónico y artístico de San Miguel de Allende, la monografía se integra de cinco partes que comprenden desde los orígenes prehispánicos hasta el siglo XX. El autor destaca de manera especial el siglo XVIII, el mayor esplendor en San Miguel, ofreciéndonos un panorama ameno e interesante de la villa: su economía, su soestas y sus magníficos monumentos civiles y religiosos durante los albores de la guerra de Independencia. Dedica un capítulo a la importante participación de San Miguel el Grande en la guerra de 1810 , centrando su atención en la figura de Ignacio Allende. Para los siglos XIX y $\mathrm{xX}$ enfoca diversos sucesos aislados relacionados con la ciudad y a notables personajes sanmiguelenses, cerrando la obra con un capítulo referente a la historia y al valor artístico del Santuario de Atotonilco. El aparato crítico se sustenta fundamentalmente en una selecta bibliografía y, en menor medida, en documentos del Archivo General de la Nación.

CRG INAH Michel, Marco Antonio, "El sistema de ciudades del s/c Bajío", en Controversia, tomo I, año II, núm. 5, Guadalajara, enero-marzo de 1978 , p. 58-65, gräf., cuads.

Este artículo intenta demostrar que el Bajío constituye, en sí mismo, una unidad de análisis clave para la comprensión del proceso histórico del país. Para tal efecto, reconstruye y explica a partir de elementos significativos, cómo la administración colonial establece en la región, "por primera vez en el mundo", un sistema de ciudades en equilibrio que se consolidará durante la Colonia y que al finalizar el siglo XIX. pasará con su propia estructura a integrarse cada vez más a la economía metropolitana. Sus fuentes son los estudios ya clásicos sobre la región del Bajío. 
BCUG

G 62.09724 MON

Monroy, Pedro L.. Las minas de Guanajuato. Memoria histórico-descriptiva de este Distrito minero, México, Secretaría de Fomento, 1888,677 p., cuads.

Hacia finales del siglo XIX. la Secretaría de Fomento ideó un magno proyecto para recopilar datos sobre el estado de la minería en el pais. Tocó a Pedro Monroy, ingeniero de minas, el encargo de escribir la memoria descriptiva de los minerales de Guanajuato. A pesar de que en este libro se insertan noticias históricas que van desde la Conquista hasta 1880 , su valor reside en el cuidadoso análisis comparativo que presenta de la geologia, la técnica y las estadisticas mineras guanajuatenses con las del resto del país y las de Europa. Es importante destacar el interés del autor por mostrar los adelantos técnicos de la época, en cuanto a la extracción y beneficio de la plata y del oro. La lectura de esta obra es indispensable para conocer el interesante proceso de transformación que el hombre ha emprendido sobre la generosa naturaleza mineral del distrito de Guanajuato.

$\begin{array}{ll}\text { AHAG } & \text { AML } \\ \text { s/c } & \text { HE3 } \\ \text { BOB NAH } & 2464 \\ \text { Rr } & \text { BMDR } \\ 972.03 & \text { s/C } \\ \text { M67m } & \\ \text { BCUG } & \\ 972.03 & \text { BC UNAM } \\ \text { MOR } & \text { F1226 } \\ & \text { M82 }\end{array}$

Mora, José Maria Luis, México y sus revoluciones (pról. de Agustin Yáñez), México, Editorial Porrúa, S. A., 1965, $2^{\mathrm{a}}$ ed., 3 vols.

El eminente intelectual y politico ha legado en esta obra una visión equilibrada y "sincera" de la historia de México. El tema central es la Independencia. que rastrea hasta sus orígenes en el siglo XvI. Conceptúa a dicho movimiento como un hecho que permite cambiar el rumbo de México al romper con España y repudiar a la Colonia. Desde este punto de vista. la revolución de 1810 se presenta como un fenómeno integral. Concluye el autor, a diferencia de Alamán, que la insurrección de Hidalgo "ha sido tan necesaria para la consecusión de la Independencia, como perniciosa y destructora del pais". En tanto que la lucha se inició en la intendencia de Guanajuato, la lectura de esta obra es indispensable para el conocimiento histórico de la región. La figura de Riaño, la personalidad de Hidalgo, el derrotero del ejército insurgente, la toma de la Alhóndiga de Granaditas y la guerra toda, encuentran en el autor a un narrador crítico de gran talla. El autor dedica varias páginas específicamente a la Provincia de Guanajuato, "la más poblada del virreinato, llena de hombres robustos y buenos jinetes, todos declarados por la insurrección..."

COLMEX 972.44 M853h

COLBAJ 972.4

M8343h
Moreno, Manuel M., Historia de la revolución en Gluanajuato, México, Patronato del Instituto Nacional de Estudios Históricos de la Revoluciôn Mexicana-Secretaría de Gobernación, 1977, 186 p.

Ante la escasez de estudios en torno al papel de Guanajuato en el proceso revolucionario iniciado en 1910, el trabajo de este exgobernador tiene el mérito de ofrecer una visión global de los acontecimientos acaecidos en el estado desde el ini- 
cio del Porfiriato hasta el año de 1917. Aunque por momentos se pierde la trayectoria estrictamente regional en la prolija narración de fenómenos nacionales, la obra arroja cierta luz sobre asuntos tan importantes como los precursores de la Revolución en el estado, las luchas electorales surgidas con el maderismo, los enfrentamientos locales entre villistas y obregonistas y la participación de los representantes de Guanajuato en el Congreso Constituyente. El libro contiene además noticias biográficas de varios guanajuatenses que destacaron en las contiendas ideológicas y políticas de la época, así como los textos de algunas proclamas y decretos gubernamentales del periodo citado. Pese a que no profundiza en las características económicas y sociales propias de la región, el autor hace algunas referencias a esos aspectos e incluye el proyecto integro de reformas constitucionales presentado por el Partido Liberal Guanajuatense en vísperas de la celebración del Congreso de 1917.

CRC INAH
S/C
BMDR
S/C

Mediante el análisis de los procesos de urbanización determinados por el factor externo de la economía novohispana, la autora define las características principales que, a finales del siglo XvIII. convierten el Bajio en un caso de "equilibrio regional", único en la Nueva España. Se explica además la formación de una red compuesta por ciudades de cierta importancia, alrededor de las cuales se desarrollan centros urbanos medianos y pequeños, todos ellos con personalidad propia. Esta situación, señala la autora, se genera por la particular infraestructura económica del Bajio y por dos características más: la movilidad interregional de sus pobladores y la acumulación y reinversión de la riqueza en el equipamiento urbano de sus ciudades. Para el estudioso de la zona del Bajío, este pequeño artículo resulta de capital importancia porque invita a la reflexión profunda de las causas que explican la conformación de una región. La utilización de padrones y censos como fuentes principales, conforma una metodología interesante.

Morin. Claude, Michoacán en la Nueva España del siglo XVIII. Crecimiento y desigualdad en una economia colonial, México, Fondo de Cultura Económica, 1979, 328 p. (Colección Tierra Firme.)

El estudio que nos ofrece el historiador canadiense Claude Morin, acerca del extenso territorio que cubría el Obispado de Michoacán en la Nueva España del siglo Xvılı, introduce nuevos elementos en el estudio en torno a los problemas de la región, que ocupa actualmente a los especialistas que analizan el centro-occidente del país. Morin toma como punto de partida los archivos parroquiales, mediante los cuales emprende la reconstrucción histórica basada en los métodos y técnicas de la historia social de la demografia francesa aplicada a la zona que abarca los actuales estados de Guanajuato y Michoacán. Aplica también nuevas ca- 
tegorias en el análisis histórico de la región, tales como dominadores-dominados. desarrollo-subdesarrollo, etc., con lo cual se aproxima a Pierre Vilar en su definición de la historia como una ciencia en construcción permanente. Una historia regional como la presentada por Morin arroja nuevas luces no sólo sobre la sociedad mexicana sino de las sociedades latinoamericanas. Partiendo de una crítica a la historiografía que alude al gran progreso que las reformas borbónicas causaron en Guanajuato y en el Bajio, analiza sucesivamente a la población, la producción y los intercambios para proporcionarnos una nueva cronologia que rompe con el tiempo político de la historiografía reinante como sustento de una nueva definición a la "naturaleza de la forma económicosocial que domina en la región motivo de estudio..." Este ambicioso proyecto sólo podrá evaluarse en la medida que esta obra tenga una influencia. o. si se quiere. encuentre continuadores entre los estudiosos de los problemas de la región.

juato y su contorno en la época virreinal", en Boletín de la Dirección de Investigaciones Historicas del Estado de Guanajuato, año 1, núm. 1. noviembre de 1978, p. 41-53.

Esta es la versión escrita de una conferencia. Proporciona una somera visión de conjunto sobre el proceso demográfico de Guanajuato durante la Colonia y, más concretamente, de mediados del siglo xvill. El estudio aporta datos estadisticos acerca de la población. la distribución espacial del crecimiento, las crisis demográficas de 1737-38 y 1786 , y sus efectos desiguales en la región. Ofrece también datos históricos de las corrientes migratorias. el mestizaje y las fluctuaciones étnicas. Basado en censos de la época. el trabajo sugiere una infinidad de posibles temas de estudio.

INAH

LBS

F 1231

M846 Vi

COLMEX

917.2

M846V
Morfi, Agustín de, Viaje de indios $y$ diario de Nuevo Mévico, noticia biobibliográfica y acotaciones de Vito Alessio Robles, México, Manuel Porrúa, S.A., 1980, 446 p.

Se trata del diario de viaje, escrito por el franciscano español que acompañó a Teodoro de Croix en su recorrido hacia las provincias internas de las que habia sido nombrado gobernador y comandante general, el cual constituye una fuente muy importante para el estudio de Nueva España a mediados del siglo XVIII. El autor plasma sus observaciones a propósito de asuntos de diversa índole, llamando constantemente la atención sobre el mal uso de muchos recursos y el triste abandono de grandes extensiones de tierras. A su paso por la recién creada Intendencia de Guanajuato, describe algunos aspectos de la vida de San Miguel el Grande y San Felipe, así como las características generales de varias haciendas. El comentario biobibliográfico que acompana la obra, esclarece algunos aspectos de la rica producción del minucioso franciscano. 

centenario de su fundación. México, s. e., 1907, 29 p.

Escrita con motivo del tricentenario de la fundación de San Francisco del Rincón, esta breve monografía proporciona una amplia información sobre la historia politica, eclesiástica, industrial y cultural de la localidad. Aunque no es éste un estudio exhaustivo, sí señala algunos aspectos fundamentales: la fundación del pueblo y su elevación a la categoría de villa y cabeza de partido, su rivalidad comercial y administrativa con la vecina población de Purísima, el desarrollo de su industria sombrerera, su importancia como centro mercantil y sus principales instituciones culturales y educativas. Aunque se trata de un panegírico, este trabajo reproduce algunos documentos relevantes para la historia francorrinconense y hace varias observaciones sobre la promisoria situación económica e industrial que vivía la ciudad a principios de siglo. En sintesis, es una de las pocas obras del género que pueden sugerir al historiador muchas vetas de trabajo aún inexploradas.

\begin{abstract}
BOB INAH
$\mathrm{Rr}$

338.2724

0761

BCUG

$\mathrm{G} 622.09724$

ORO

Orozco, Rafael, La industria minera de México. Distrito de Guanajuato, México, SEP.. Dirección de Talleres Gráficos, 1921, 167 p.

Siguiendo el esquema tradicional de los trabajos geográficas y geológicas del distrito de Guanajuato para ofrecer un panorama histórico general de sus vetas, minerales, compañias, minas y haciendas de beneficio, deteniéndose básicamente en los aspectos económicos y técnicos. Se trata de una publicación oficial, promovida por el Instituto de Geología de la Secretaría de Industria, Comercio y Trabajo, cuyo autor, ingeniero de minas, aclara en el prólogo no haber intentado escribir nada nuevo sobre el tema, sino más bien extractar la información contenida en varias fuentes secundarias. No obstante, y ante la dispersión de la información sobre la minería, la obra tiene la virtud de dar una visión de conjunto y de mostrar la situación y perspectivas de las minas en 1921.
\end{abstract} cía. Episodios de la vida y campañas del genial guerillero. México, Editorial "México Nuevo", 1940. 250 p., ils.

Esta obra se acerca más al género literario que al histórico. Se desarrolla en torno a la figura de Albino García, trabajador agrícola y guerrillero del Bajio, siguiendo una cronología rigurosa desde septiembre de 1810 hasta junio de 1812 . Describe el paisaje rural y las tácticas guerrilleras. haciendo patente la crueldad y los ardides de la guerra. Narra el asalto a los convoyes que viajaban por la ruta de la plata y destaca el conocimiento que de la geografía de la región tenian los insurgentes y adquirieron los realistas a través de sus campañas. Proporciona, además, noticias interesantes sobre la fabricación de cañones, la acunación de la moneda, así como del 
estado de la agricultura y de la minería. Complementan esta obra una serie de apéndices documentales que incluyen rimas populares de la época.

BEV MAG Poij-335

(72)

Poinsett, Joel R., Notas sobre México, México, Editorial Jus. $1950,510 \mathrm{p}$.

No podía el autor, en su condición de explorador de México con miras al expansionismo norteamericano, dejar de visitar la rica región del Bajío. Sus cartas de viaje comprenden varias descripciones generales de los valles agricolas, algunas ciudades y caminos principales y la actividad minera de Guanajuato y sus alrededores. Sin la cultura de Humboldt ni la minucia de Ward, esta obra refleja una de las primeras visiones extranjeras sobre Guanajuato después de la Independencia y los muy particulares puntos de vista de un abierto partidario de la Doctrina Monroe.

BCUG

Rangel Camacho, Manuel, Cuarto Centenario de Nuestra Señora de Guanajuato, Cuernavaca, Manuel Quesada Brandi Editor, 1969, 426 p., ils.

Esta edición fue preparada para conmemorar el IV centenario y las bodas de oro de la Coronación Pontificia de Nuestra Señora de Guanajuato. Incluye el texto de la conferencia dictada con ese motivo por el historiador Antonio Pompa y Pompa, quien elabora una síntesis histórica de la ciudad, de la tradición e historia de la imagen de la Virgen y de las manifestaciones del culto a la advocación mariana en Guanajuato durante la Colonia. Por su parte, Rangel Camacho se ocupa de la tradición devota desde los inicios de la guerra de Independencia hasta nuestros días, insertando una selección de documentos, sermones, discursos y poesías en torno a la venerada efigie. El libro contiene interesantes apéndices, facsimilares, fotografías e ilustraciones, que contribuyen a integrar una parte fundamental de la historia eclesiástica de la ciudad.

BOB INAH

323.272

R45r

AHUG

s/c

AHAG

$\mathbf{s} / \mathrm{c}$

Reina, Leticia, "Sierra Gorda: Guanajuato, Querétaro y San Luis Potosi", en Las rebeliones campesinas en México (1819-1906), México, Siglo XXI Editores, 1984 , p. $291-321$.

La sección de este libro relativa a la Sierra Gorda, refiere de manera sucinta la historia del levantamiento campesino iniciado en la localidad en 1847 y sofocado por las fuerzas federales en los primeros años del Porfiriato. Enriquecido con la reproducción de los textos emanados del movimiento en sus diferentes etapas, algunos de interesante tinte socialista, el estudio señala los vínculos de la rebelión con algunas luchas por el poder central e ilustra la efervescencia característica de la zona durante más de tres décadas. Así pues, su lectura ofrece un buen panorama general de un conflicto agrarista que aún no ha sido estudiado exhaustivamente. 


\begin{abstract}
BCUG Rionda Arreguín. Isauro, Haciendas de Guanajuato: G72 4102 Tesoros de la arquitectura. Testigos de la historia, RIO Guanajuato, Gobierno del Estado, 1985, 140 p., ils. AHAG El autor es el cronista de la ciudad de Guanajuato s/c y relata los hechos históricos de treinta y dos haciendas del estado, desde sus orígenes en el siglo XvI. hasta el año de 1910. Su importancia radica en ser la única publicación que reúne datos sobre tantas propiedades rurales. No obstante, es de lamentar que con tal acervo documental, la obra no trascienda al terreno meramente descriptivo. Contiene un valioso material gráfico.
\end{abstract}

\begin{abstract}
INAH Rodriguez Frausto, Jesús, La huella de Juárez en FI 233 Guanajıato, Guanajuato, Universidad de GuanaJP juato, 1972, $277 \mathrm{p}$.

R6 Publicada con motivo del centenario del falleci9720511 miento de Benito Juárez, esta obra intenta señalar R6962h algunos antecedentes de la Reforma contenidos en las ideas insurgentes, a la vez que describir el paso del Benemérito por Guanajuato, en el contexto de las luchas entre liberales y conservadores. Echa mano de un sinnúmero de documentos y testimonios periodisticos, muchos de los cuales se intercalan textualmente con la narración; el autor arroja cierta luz sobre la posición y participación de Guanajuato en los conflictos de la época, una de las menos trabajadas de la historia regional. Sin embargo, los constantes elogios a los liberales, la inclusión de muchos datos poco relevantes y las interpretaciones que a veces se quedan en la superficie, son elementos que restan a este trabajo la profundidad que seria deseable.
\end{abstract}

BOB INAH Rodriguez Frausto, Jesús, Sóstenes Rocha, México,

C831

No. 77

AHUG

s/c SEP.. 1967, 110 p. (Serie La Victoria de la República.)

Dada la escasez de estudios históricos que aborden apasionamiento la acción de varios personajes guanajuatenses del siglo XIX (Manuel Doblado, Florencio Antillón, Sóstenes Rocha. Santos Degollado, etc.), es menester recurrir, para cubrir parcialmente la información, a algunas de las múltiples biografías realizadas por los historiadores locales. Tal es el caso de este trabajo sobre Sóstenes Rocha, quien si bien se desempeñó fundamentalmente fuera de Guanajuato, es hijo reconocido de ese estado. En un intento de justificar la a veces contradictoria participación del militar en las luchas de su tiempo, el autor describe su trayectoria sin ahondar en matices ideológicos o problemas interpretativos. En consecuencia, faltan análisis sistemáticos y profundos que aporten un nuevo enfoque sobre estas figuras locales.

COlbaj Rodríguez Gómez, María Guadalupe, Jalpa y San $\mathbf{s} / \mathbf{c}$

AHAG

$\mathrm{s} / \mathrm{C}$

BCUG

$\mathrm{G}$

972.41

ROD Jian de los Otates. Dos haciendas en el Bajio colonial, León, El Colegio del Bajio, A. C., 1984, 172 p., plans., maps., cuads., gráfs.

A través del análisis comparativo de dos haciendas de la región noroccidental del Bajío (1542-1810), este trabajo muestra la articulación de la actividad 
agropecuaria con el proceso socioeconómico regional y su integración a las actividades empresariales de los propietarios. La autora encuentra algunos rasgos distintivos de las grandes fincas rurales abajeñas, como resultado de una investigación minuciosa y bien documentada.

COLMEX 917.244 R $741 \mathrm{~V}$

\section{Luz, 1969, 338 p}

Rojas, Basilio, Valle, corazón del Bajio: sintesis geográfica, económica, estadistica y social del municipio de Valle de Santiago, Guanajuato, México, Editorial

Valle de Santiago es sin duda el municipio guanajuatense que más ha atraido la atención de los investigadores, debido quizá a las muy particulares condiciones de su estructura agraria y su vida social. Este trabajo describe esos aspectos, rastreando el desarrollo de la localidad desde la época prehispánica hasta nuestros días. Basado fundamentalmente en las obras de José Guadalupe Romero y Pedro González, asi como en varias fuentes documentales de primera mano, el autor aporta elementos para comprender la economia y la sociedad vallenses, e incluye algunas sintesis biográficas de sus hombres más ilustres.

BCUG

$\mathrm{G} 917.24$

ROJ

Rojas Garcidueñas, José, Salamanca. Recuerdos de mi tierra guanajuatense, México, Editorial Porrúa, 1982, 237 p., ils.

Con objeto de escribir la historia de su terruño, el autor se concreta a narrar lo que estuvo relacionado directamente con Salamanca. Su estudio abarca desde el siglo XVI hasta el año de 1900, basándose en una periodización propuesta por el autōr para la historia de la localidad. Alude en forma detallada a los hechos nacionales y estatales que intervienen en el proceso de la ciudad, destacando las noticias geográficas, estadísticas y descriptivas, así como las tradiciones salmantinas de fines del siglo pasado. La obra no es producto de una investigación sistemática, como el mismo autor lo declara en el prólogo, sino el fruto de una paciente reunión y ordenamiento de datos procedentes de fuentes secundarias, documentos de su archivo particular, tradiciones orales y memorias personales. La obra va acompanada de apéndices y fotografías pero no contiene bibliografía.

$\begin{array}{ll}\text { COLBAJ } & \text { BOB INAH } \\ 972.37041 & 972.34 \\ \text { R } 763 \mathrm{~m} . & \text { R } 65 \mathrm{~m} \\ \text { COLMICH } & \\ 20409 & \\ 972.37 & \\ \text { ROMm } & \end{array}$

Romero, José Guadalupe, Michoacán y Guanajuato en 1860: Noticias para formar la historia y estadistica del Obispado de Michoacán, (ed. facsimilar) Morelia, FIMAY, 1972, 252 p., ils.

Editado por vez primera precisamente en el año en que Guanajuato dejó de pertenecer al obispado de Michoacán, este libro reúne un sinnúmero de datos sobre la historia y la geografía de esa diócesis, ilustrados con mapas y estadísticas. Se hace un recuento minucioso de las características y riquezas del obispado, que aunque carece de interpretación, cons- 
tituye, sin embargo una fuente clásica y proporciona abundante material al investigador. Habiendo sido escrito por un canónigo durante el movimiento de Reforma, el libro aporta interesante información sobre el patrimonio del clero regular y secular, la desamortización de sus bienes, etcétera.

BCUG

$\mathrm{G}$

1967

ROS

BOB INAH

972.06

R68r.

Ross, William John II, The role of Manuel Doblado in the Mexican Reform movement. 1855-1860, Austin, The University of Texas, 1967, $366 \mathrm{p}$.

Resultado de casi diez años de investigación, esta obra se centra en los cinco años cruciales de la vida de Manuel Doblado, tanto para la política de su estado natal, como para la de la nación en general. A diferencia de la mayoría de los textos referentes a este personaje, los cuales suelen quedarse en los límites de la pura biografia, este trabajo alude a aspectos tan importantes como la actitud de Doblado frente al federalismo, su postura ante la relación Iglesia-Estado, sus concepciones sobre el papel del ejército, etc. Basado en fuentes de primera y segunda mano, este libro ilustra la posición vanguardista que ocupa Guanajuato en el movimiento de Reforma.

BOB INAH

972.41

Sánchez de Tagle, Esteban, Por un regimiento del régimen. Politica y' sociedad: la formación del regimiento de Dragones de la Reina en San Miguel el Grande.

1774. México, Departamento de Investigaciones Históricas, INAH. 1982, 95 p.. cuads., maps., gráfs. (Colección Científica, Historia Social, 129).

Desde una perspectiva novedosa, en este trabajo se analiza el proceso de formación de un cuerpo miliciano y su relación con la estructura social representada por el grupo criollo que detentaba el poder económico local. La conciencia de autosuficiencia regional, producto del particular desarrollo del complejo económico del Bajio, aunada al poder político que la metrópoli ejercía en sus colonias durante los últimos años del siglo XVIII, abrió nuevos canales de expresión que permitieron a los criollos plantear sus exigencias frente a la Corona, a partir de la organización de las propias milicias. Es particularmente interesante el material de archivo en que se apoya la obra.

COLMEX

972.03

T 243s

Taylor, James Williams, Socioeconomic instability and the revolution for Mexican independence in the Province of Guanajuato, Albuquerque, University of New Mexico, 1976, 322 p.

Esta tesis de grado tiene por objeto estudiar las verdaderas causas que dieron lugar al movimiento de Hidalgo en Guanajuato, poniendo con ello a prueba los motivos que tradicionalmente se atribuyen a esa revolución. El estudio gira alrededor de la muy particular estructura socioeconómica de la Intendencia, analizando el impacto que tuvo en ella la política de la metrópoli y 
haciendo hincapié en las diferencias que existian entre la rigidez de su ciudad capital y la relativa movilidad social de la zona rural y de otras poblaciones guanajuatenses. Desde esta perspectiva, el autor muestra el porqué del surgimiento de la Independencia precisamente en Guanajuato y el peso que tuvo en ella el fuerte ingrediente criollo de sus habitantes. Re'ports. Authoritative Endorsements. Some Letters. Together with Detailed Reference to the Physical and Financial Features of the Peregrina Mining Properties, Nueva York. The Cheltenham Press. 1905. 36 p., ils., map.

Este libro comprende los informes realizados por varios especialistas norteamericanos sobre La Peregrina, a petición de la compaǹia que explotaba el fundo. El objeto era ofrecer a los inversionistas estadunidenses las seguridades de un negocio lucrativo y atraer nuevos accionistas a la empresa minera. Los diversos trabajos que incluye brindan una detallada relación de las caracteristicas físicas y económicas de las propiedades de la corporación. Incluye material fotográfico interesante y un mapa del perfil de la mina.

BIM

B

013.22

VAL.1

Valverde y Téllez, Emeterio, Biobibliografia eclesiástica mexicana, 1821-1943. México, Editorial Jus, 1949,3 vols.

Esta vasta obra constituye uno de los pilares de la historiografía eclesiástica mexicana durante el periodo republicano. El autor, que fuera obispo de León, formado durante la crisis que vive la Iglesia después de la caída del segundo Imperio, se entregó a la empresa de recabar todo el material biobibliográfico de las grandes figuras del clero mexicano. Dados sus vínculos con la diócesis leonesa. el autor maneja amplia información sobre muchos sacerdotes guanajuatenses. destacando entre ellos el también obispo Díez de Sollano y Dávalos.

$\begin{array}{ll}\text { INAH } & \text { AHUG } \\ \text { LBS } & \text { S/C } \\ \text { F1281 } & \\ \text { V297i } & \text { AHAG } \\ \text { INAH } & \text { S/c } \\ \text { L.G.O. } & \text { BM } \\ \text { F1281 } & 972.44 \\ \text { V37 } & \text { V297i } \\ \text { AML } & \text { COLMEX } \\ \text { HE2 } & 972.44 \\ 2422 & \text { V297i } \\ \text { BNAL } & \\ \text { 972.03 } & \\ \text { VR.i } & \end{array}$

Vargas, Fulgencio, La insurrección de 1810 en el Estado de Guanajuato: heroismos, campañas, martirios y sacrificios de los primeros insurgentes. Tradiciones y levendas (pról. de Luis González Obregón, juicio crítico Juan de Dios Peza), México, Eusebio Gómez de la Puente Editor, 1909, 153 p., ils.

Más que producto de una tarea de investigación historiográfica, esta pequeña obra es la narración literaria de un conjunto de sucesos, leyendas y tradiciones contados con el calor apasionado del provinciano que rescata los hechos de hom- 
bres y mujeres de su región. El libro fue escrito para conmemorar el centenario de la Independencia y ha sido calificado por sus criticos como literątura patria. Por su misma naturaleza, no señala la procedencia de sus datos.

Vargas. Fulgencio, Santiago Silagua. Ensayo monográfico de la municipalidad de Silao, conmemorativo del cuarto centenario de la fundación de su Cabecera, Guanajuato, Gobierno del Estado, 1937, 32 p.

V297

Esta obra conmemora la fundación de Santiago Silagua (hoy Silao de la Victoria), rescatando noticias breves sobre la historia del lugar y su estratégica situación geográfica. Para destacar la importancia de la localidad en la vida nacional, el autor alude a las batallas libradas en su jurisdicción entre liberales y conservadores. El folleto contiene un apartado con las efemérides silaoenses más notables a lo largo de cuatrocientos años.

$\begin{array}{ll}\text { COLMEX } & \text { COLBAJ } \\ 972.44 & 972.413 \\ \text { V433 h } & \text { V4345h } \\ \text { INAH } & \text { AML } \\ \text { LBS } & \text { HE2 } \\ \text { F1391 } & 2424-2427 \\ \text { C3 } & \text { AHUG } \\ \text { V4 } & \text { S/C } \\ \text { BCUG } & \\ \text { G } & \\ 972.417 & \\ \text { VEL } & \end{array}$

Velasco y Mendoza, Luis, Historia de la ciudad de Celaya. México, Imprenta de Manuel León Sánchez, 1947-1949. 4 vols., ils.

Esta obra ofrece una visión panorámica de la historia de Celaya y alude a muchos aspectos del proceso general del estado. Partiendo de la época prehispánica, abarca hasta la presidencia de Alvaro Obregón y aborda los fenómenos regionales en el contexto de la vida nacional. Detalla noticias de la ciudad y el municipio celayense, algunos gobernadores de la entidad y diversos sucesos notables. Así pues, proporciona en su conjunto una interesante sintesis histórica regional. Su aparato crítico se basa en material bibliográfico, hemerográfico y de archivo. ricano. Descripción general de los reinos y provincias de la Nueva España y sus jurisdicciones. Dedicala al Rey Nuestro Señor al señor don Fernando VI, monarca de las Españas, 1798, México, Imprenta de la viuda de Joseph Bernardo de Hogal, 1952, 4 vols.

Este trabajo, realizado por encargo del virrey Fuenclara a mediados del siglo XVIII. no constituye una historia propiamente dicha, sino una fuente de datos recogidos por el cientifico novohispano Villaseñor y Sánchez. Los seis capitulos que dedica a Guanajuato contienen información histórica y geográfica, así como descripciones muy generales de sus principales poblaciones. Sin abundar demasiado en ningún aspecto específico, ya que el objetivo de la obra era hacer una especie de inventario de la Colonia, el autor consigna los limites, las manufactu- 
ras, los conventos, los caminos y otros elementos de las villas, haciendas y ranchos guanajuatenses. Pese a su carácter sintético, o más bien gracias a éste, la obra proporciona un instrumento muy adecuado para una aproximación general a la región en el periodo citado.

AHAG

Villegas, Victor Manuel, Arle popular de Guanajuato $\mathrm{s} / \mathrm{c}$ (pról. de Martín Luis Guzmán), México, Banco Nacional de Fomento Cooperativo, S. A. de C. V., 1964, 2 vols., ils.

Con el propósito de dar a conocer la tradición artesanal guanajuatense, este estudio se ubica en un amplio marco de referencia sobre la aceptación universal del arte popular. El autor logra hacer de su obra un catálogo de las expresiones populares regionales que comprenden las artes mayores y menores, desde la arquitectura hasta los tejidos, pasando por toda una gama de materiales, texturas, formas, técnicas y utensilios. En el estado de Guanajuato son muchos los municipios que por la habilidad manual de sus artesanos, recogen la tradición popular y secular y la vuelcan en variados objetos, útiles y decorativos, los cuales constituyen una de las manifestaciones de su cultura y de su historia.

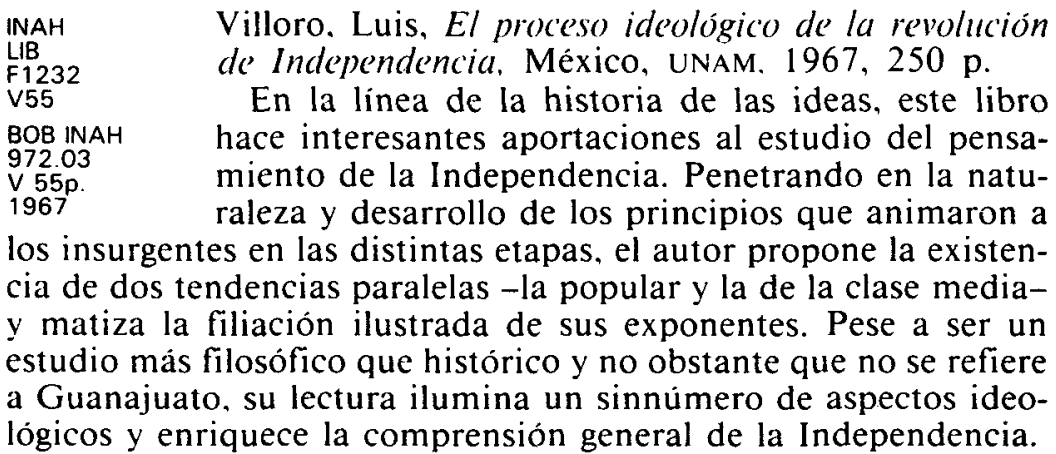

colbaJ Ward, Henry G., Mévico en 1827 (trad. de Ricardo 972.05 Hass), México, Fondo de Cultura Económica, 1981, AHAG $788 \mathrm{p}$.

s/c Este viajero británico, encargado de negocios de la

Corona, recorrió con especial atención el Bajio, interesado como estaba en las inversiones de capital inglés en la minería. Su diario contiene. entre muchas otras cosas, descripciones detalladas de los procesos de extracción y beneficio con comentarios sobre su costo y eficacia, relaciones minuciosas de las costumbres mineras y frecuentes observaciones sobre el desempeño de las compañias anglosajonas en los minerales de Guanajuato. De amena lectura, la obra se detiene también en la geografía, la agricultura, la población, los centros urbanos y los caminos. lamentando a veces la devastación causada por la guerra de Independencia, expresando su admiración ante ciertos usos y paisajes, pero deseando siempre un futuro promisorio para los intereses de su patria. 


\begin{abstract}
AHAG $\mathrm{S} / \mathrm{c}$

Wolf, Eric R., "El Bajío en el siglo xvIII. Un análisis

BMDR

S/c de integración cultural" en David Berkin (comp.),

INAH

LBS

F1281

W853w

Los heneficiarios del desarrollo regional, México, SEP. 1972. p. 63-95 (Colección Sep-Setentas, 52). New Orleans, Middle American Research Institute, Tulane Uni-

"The Mexican Bajio in the Eighteenth Century. An versity, 1955, p. 177-260.

Se trata de un articulo que arroja interesantes apreciaciones sobre el desarrollo económico que alcanzó el Bajio durante el siglo XVIII. Tal desarrollo conformó un complejo regional único en la Nueva España, el cual aceleró la evolución de una serie de formas productivas propias de la zona, generando la integración de una estructura muy particular. Las características económicas, sociales. culturales e ideológicas del Bajio constituyen para el autor la clave para la comprensión del surgimiento de la Independencia. Es importante subrayar que la versión española no contiene las referencias a las fuentes, por lo que se sugiere consultar el original en inglés.
\end{abstract}

BIBI.IOHECAS CONSULIINDAS

AHAG; $\quad$ Archivo Histórico de la Alhóndiga de Granaditas. Museo Regional de Guanajuato. INAH.

AHIG: Archivo Histórico de la Universidad de Guanajuato. Facultad de Filosofia y Letras. Universidad de Guanajuato.

AML: Archivo Municipal de León.

B^O UG: Biblioteca "Armando Olivares". Universidad de Guanajuato.

BCUC: $\quad$ Biblioteca Central de la Universidad de Guanajuato.

BC INAM: Biblioteca Central de la Universidad Nacional Autónoma de México.

BILL: Biblioteca "Familia Leal".

BFM LG: Biblioteca de la Facultad de Minas. Universidad de Guanajuato.

BIM: Biblioteca del Instituto de Investigaciones Doctor José Maria Luis Mora.

B.M: $\quad$ Biblioteca de México.

BMDR: $\quad$ Biblioteca Museo Casa Diego Rivera.

BNAL: Biblioteca Nacional de México. UNAM.

BOB INAH: Biblioteca "Orozco y Berra". INAH.

COLBAJ: Biblioteca de El Colegio del Bajio.

(OlmEX: Biblioteca de El Colegio de México.

(COLMICH: Biblioteca de El Colegio de Michoacán.

CONDUMEX: Centro de Estudios de Historia de México.

CRG INAH: Biblioteca del Centro Regional Guanajuato, INAH.

IIE IINAM: Biblioteca del Instituto de Investigaciones Estéticas, UNAM.

IIH IINAM: Biblioteca del Instituto de Investigaciones Históricas. UNAM.

IVAH: Biblioteca del Instituto Nacional de Antropología e Historia. 